NBER WORKING PAPER SERIES

\title{
HEALTH INSURANCE AND TRAFFIC FATALITIES: THE EFFECTS OF SUBSTANCE USE DISORDER PARITY LAWS
}

\author{
Ioana Popovici \\ Johanna Catherine Maclean \\ Michael T. French \\ Working Paper 23388 \\ http://www.nber.org/papers/w23388 \\ NATIONAL BUREAU OF ECONOMIC RESEARCH \\ 1050 Massachusetts Avenue \\ Cambridge, MA 02138 \\ May 2017, Revised February 2018
}

Previously circulated as "The Effects of Health Insurance Parity Laws for Substance Use Disorder Treatment on Traffic Fatalities: Evidence of Unintended Benefits." We thank Monica Deza and seminar participants at the 2016 Association for Public Policy and Management Fall Research Conference for helpful suggestions. We appreciatively acknowledge Tonja Lindsey at the National Center for Statistics and Analysis Office of Traffic Records and Analysis, National Highway Traffic Safety Administration, for her assistance with the FARS data. We are also grateful to Colleen Barry, Susan Busch, Gulcin Gumus, Rosalie Pacula, and Jonathan Woodruff for sharing data with us. All errors are our own. The views expressed herein are those of the authors and do not necessarily reflect the views of the National Bureau of Economic Research.

NBER working papers are circulated for discussion and comment purposes. They have not been peer-reviewed or been subject to the review by the NBER Board of Directors that accompanies official NBER publications.

(C) 2017 by Ioana Popovici, Johanna Catherine Maclean, and Michael T. French. All rights reserved. Short sections of text, not to exceed two paragraphs, may be quoted without explicit permission provided that full credit, including $\odot$ notice, is given to the source. 
Health Insurance and Traffic Fatalities: The Effects of Substance Use Disorder Parity Laws Ioana Popovici, Johanna Catherine Maclean, and Michael T. French

NBER Working Paper No. 23388

May 2017, Revised February 2018

JEL No. I1,I13,I18

\begin{abstract}
$\underline{\text { ABSTRACT }}$
Each year, approximately 10,000 individuals die in alcohol-impaired traffic crashes in the United States, while psychoactive drugs are involved in $20 \%$ of all fatal traffic crashes. In this study, we investigate whether state-specific parity laws for substance use disorder (SUD) treatment have the added benefit of reducing traffic fatalities. Parity laws compel insurers to generously cover SUD treatment in private markets, thereby reducing the financial costs of and increasing access to treatment for beneficiaries. We employ 23 years of administrative data from the Fatality Analysis Reporting System (FARS) coupled with a differences-in-differences design to investigate the potential spillover effects of parity laws to traffic safety. Our findings indicate that passage of a parity law reduces traffic fatality rates by 5.8 to $8.6 \%$. We also find that passage of parity laws reduces fatal alcohol poisonings and psychoactive drug overdoses. These findings suggest that government regulations requiring insurers to cover SUD treatment can significantly improve traffic safety, possibly by reducing the number of impaired drivers on roadways.

Ioana Popovici

Department of Sociobehavioral and

Administrative Pharmacy

Nova Southeastern University

3301 College Avenue

Fort Lauderdale, FL 33314-7796

ip153@nova.edu

Johanna Catherine Maclean

Department of Economics

Temple University

Ritter Annex 869

Philadelphia, PA 19122

and NBER

catherine.maclean@temple.edu

Michael T. French

Professor of Health Economics

University of Miami

Department of Sociology

5202 University Drive

Merrick Building, Room 121

P.O. Box 248162

Coral Gables, FL 33124-2030

mfrench@miami.edu
\end{abstract}




\section{Introduction}

Substance-impaired driving is a serious public safety concern as individuals who choose to drive while impaired increase the risk of traffic crashes for themselves, their passengers, and other drivers with whom they share roadways. In 2014, motor vehicle traffic crashes were the second leading cause of injury-related death in the United States with 36,161 deaths (Centers for Disease Control and Prevention, 2015a). Annually, approximately 10,000 individuals are killed in alcohol-impaired traffic crashes in the U.S., representing nearly one third of all traffic-related deaths, while psychoactive drugs are involved in $20 \%$ of all fatal traffic crashes (National Center for Statistics and Analysis, 2016). Moreover, the annual societal costs of alcohol-involved fatal crashes is estimated to be over $\$ 75$ billion Zaloshnja, Miller, and Blincoe (2013). ${ }^{1}$ In response to these high costs, governments at all levels have taken steps to reduce impaired driving, including imposing maximum allowable blood alcohol concentration (BAC) thresholds for drivers, prohibiting driving while under the influence of psychoactive drugs, instituting roadside sobriety check points, setting minimum prison sentences and/or financial penalties for those found guilty of driving under the influence of alcohol or psychoactive drugs, and financing public media campaigns that outline the dangers and costs of impaired driving.

The above-noted policies attempt to directly regulate or address substance use among drivers, but fail to acknowledge that substance use disorders (SUDs) are chronic, addictive diseases that should be treated through medical interventions rather than punitive public policies (Popovici, French, \& McKay, 2008). For individuals who suffer from these chronic conditions, a more effective policy approach is to address their SUDs through the promotion of effective and affordable treatment (Reuter \& Pollack, 2006; Stewart, Gossop, \& Marsden, 2002). Treating

\footnotetext{
${ }^{1}$ This estimate is adjusted from 2010 dollars (as reported in the cited manuscript) to 2017 dollars using the Consumer Price Index-Urban Consumers-by the authors.
} 
individuals with SUDs should decrease the number of impaired drivers on roadways, and hence substance-use-attributable traffic crashes.

The effectiveness of numerous SUD treatment modalities is well-established (Bondurant, Lindo, \& Swensen, 2016; Kunz, French, \& Bazargan-Hejazi, 2004; Lu \& McGuire, 2002; Popovici \& French, 2013b; Rajkumar \& French, 1997; Reuter \& Pollack, 2006; Stewart et al., 2002; Swensen, 2015), offering a potential pathway whereby SUD treatment can reduce traffic fatalities. Indeed, a study by Freeborn and McManus (2010) finds that one additional specialty SUD treatment facility per U.S. county can decrease the number of county-level alcohol-related traffic fatalities by $15 \%$ per year.

Despite established effectiveness of numerous SUD treatment modalities, many individuals who could benefit from such treatment do not receive it. While approximately 22 million people aged 12 or older displayed patterns of substance use and could have benefited from specialty SUD treatment in $2015,^{2}$ only $10.8 \%$ of these individuals received such treatment (Center for Behavioral Health Statistics and Quality, 2016). Among individuals seeking treatment, commonly cited barriers are cost and lack of insurance coverage (Substance Abuse and Mental Health Services Administration, 2016). These barriers could be diminished by ensuring equitable and affordable coverage of SUD treatment in insurance plans.

Within the U.S., public as well as private insurance plans have historically covered SUD treatment less generously than medical/surgical treatment (Starr, 2002). For example, patient cost-sharing (e.g., copayments, deductibles) has historically been higher for SUD treatment and insurers have tended to restrict such treatment utilization (e.g., setting annual or lifetime

\footnotetext{
${ }^{2}$ Specialty SUD treatment is offered in a hospital, a residential facility, an outpatient treatment facility, or other location with a licensed SUD treatment program that offers the following services: (i) outpatient, inpatient, or residential/rehabilitation treatment; (ii) detoxification; (iii) opioid treatment; and/or (iv) halfway-house services.
} 
maximums on treatment episodes, use of prior authorization, or stepped therapy) to a greater extent than other medical/surgical procedures. These barriers likely dissuade many individuals from seeking care, or obtaining adequate care, ${ }^{3}$ for their SUDs.

In the present study, we examine whether state-specific equal coverage laws for SUD treatment (often referred to collectively as 'parity laws') affect a secondary outcome—-fatal traffic crashes. State parity laws regulate private insurance markets and expand affordable coverage for alcohol and psychoactive drug treatment by requiring insurers to provide SUD treatment services at 'parity' with medical/surgical services in terms of cost sharing, nonquantitative barriers to treatment, and service restrictions. ${ }^{4}$ As state parity laws increase coverage for SUD treatment, and therefore lower out-of-pocket financial costs and increase access to individuals, standard health economic theory predicts that these regulations will increase the probability that individuals with SUDs will seek treatment (Grossman, 1972). Indeed, previous research reports that these laws and other insurance expansions increase SUD treatment utilization (Dave \& Mukerjee, 2011; McConnell, Ridgely, \& McCarty, 2012; Wen, Cummings, Hockenberry, Gaydos, \& Druss, 2013; Wen, Hockenberry, Borders, \& Druss, 2017). To explore this question, we analyze 23 years (1988 to 2010) of administrative data from the Fatality Analysis Reporting System (FARS). During this period, 12 states passed a law that required parity in terms of cost-sharing, service use, and so forth for both alcohol and psychoactive drug treatment vis-à-vis medical/surgical services in private insurance contracts, offering a novel quasi experiment. We apply differences-in-differences methods and control for

\footnotetext{
${ }^{3}$ That is care that is of reasonable duration and is matched to patient need (National Institute on Drug Abuse, 2012). ${ }^{4}$ We note that some states have passed laws that increase coverage for SUD treatment services in private contracts, but do not require equal coverage. For example, requiring insurers to offer SUD treatment to beneficiaries or to cover a specified set of services, but permitting higher cost-sharing and/or service limitations for SUD treatment visà-vis medical/surgical services. We focus our analysis on full parity laws for alcohol and psychoactive drugs.
} 
a wide range of time-varying state-specific characteristics, including state-specific trends.

Reduced substance use and abuse is the key channel through which we expect parity laws to impact traffic crashes. Thus, we also examine the effect of state parity laws on fatal alcohol poisonings and drug overdose deaths—a proxy for substance use and abuse (Swensen, 2015)— within the general adult population (i.e., the population most likely to be affected by parity laws).

The paper proceeds as follows. Section 2 provides a conceptual framework to establish a theoretical foundation for the effects of parity laws on traffic crashes and reviews the related literature. Data and methods are presented in Section 3, and the main results are reported in Section 4. Extensions and robustness checks are discussed in Section 5. Section 6 concludes.

\section{Conceptual framework and related literature}

\subsection{Conceptual framework}

In standard health economics models, healthcare demand is derived from individuals' demand for health (Grossman, 1972). Stated differently, consumers do not demand healthcare in isolation, but rather desire the associated health improvements. Individuals maximize a utility function conditional on prices of healthcare and other goods/services, preferences, health stock, and other factors that determine health (e.g., ability, type of employment, education), subject to a standard budget constraint. Healthcare price changes have standard effects on quantity demanded; i.e., an inverse relationship. ${ }^{5}$

Insurance coverage for healthcare reduces the out-of-pocket price faced by consumers. The Grossman model predicts that, in line with basic demand theory, any policy that reduces price should increase the quantity demanded (ceteris paribus). Following passage of a state parity law for SUD treatment, the price of SUD treatment should fall for privately insured

\footnotetext{
${ }^{5}$ We leverage economic intuition offered by the Grossman model rather than testing specific predictions generated by the model (Cawley \& Ruhm, 2012).
} 
patients whose insurance contracts are affected by the passage of such laws. As a result, in the aggregate (because not all people require or seek SUD treatment), we expect the quantity of SUD treatment consumed to increase for these individuals.

This proposition assumes that insurance expansions, and the ensuing reductions in out-ofpocket prices faced by privately insured consumers, will translate directly into increases in the quantity of SUD treatment demanded. Nevertheless, several factors related to consumers with SUDs and the availability of such treatment may dilute the effects of parity laws on SUD treatment and their impact on substance use-related traffic fatalities.

First, the majority of individuals suffering from SUDs do not feel that they need treatment (Substance Abuse and Mental Health Services Administration, 2016). Changes in SUD treatment price and access that occur following an insurance expansion are unlikely to affect the quantity of SUD treatment demanded by these individuals. Even among those who admit that they need treatment, other barriers such as the stigma associated with SUDs could deter treatment-seeking.

Second, due to ex ante moral hazard, expanded insurance coverage for SUD treatment could lead to increased substance use by lowering the overall costs of SUDs, in particular treatment costs (Klick \& Stratmann, 2006). Similarly, access to insurance may reduce the price of addictive medications (e.g., prescription opioids and sedatives), either the financial price of these medications or the non-financial costs (e.g., ability to access healthcare providers who can prescribe these medications), and, in turn, increase use. Finally, if addictive substances are normal goods and insurance coverage acts as an in-kind income transfer for consumers who gain coverage, passage of a parity law could increase substance use and, as a result, traffic fatalities. 
Third, many SUD treatment providers often operate at or near full capacity and their ability to respond to sizable increases in treatment demand due to passage of parity laws is limited (Andrews et al., 2015). Providers might also lack the administrative resources (e.g., electronic billing encounter systems and staff trained in billing procedures) to obtain compensation from private insurers for their services (Buck, 2011).

\subsection{Related literature}

In reviewing the literature that examines the effects of private insurance expansions on SUD treatment utilization and financing, we concentrate on studies that are most comparable to ours - those that leverage quasi-experimental variation induced by federal- or state-level law changes. $^{6}$

In 2001, a Presidential Directive in the Federal Employees Health Benefits (FEHB) Program required parity between behavioral and medical services in terms of cost-sharing, deductibles, lifetime and annual expenditures, and service limitations for federal employees and their dependents. Three studies demonstrate that SUD treatment parity due to the FEHB program modestly increased treatment use (Azzone, Frank, Normand, \& Burnam, 2011; Goldman et al., 2006; Lo Sasso \& Lyons, 2004). ${ }^{7}$

Using changes in insurance coverage caused by a large-scale healthcare reform program in Massachusetts, Meara et al. (2014) find declines in SUD-related emergency department episodes and inpatient hospitalizations among young adults. ${ }^{8}$ These results suggest expanded outpatient SUD treatment services utilization in this population. Maclean and Saloner (2017),

\footnotetext{
${ }^{6}$ We note that a much larger literature examines the impact of insurance broadly defined on SUD treatment. .

${ }^{7}$ The population affected by this program (federal employees) is heavily screened for SUDs pre-employment, thus demand for treatment within this population is likely limited. Nevertheless, a substantial share of FEHB enrollees consists of spouses and dependents who are not subject to such screening.

${ }^{8}$ We note that the Massachusetts reform, which was implemented with the goal of achieving universal coverage, increased both private and public insurance.
} 
analyzing data from the National Survey of Substance Abuse Treatment Services (N-SSATS), find that the Massachusetts reform increased admissions to specialty SUD treatment. ${ }^{9}$

Using data from California, Golberstein et al. (2015) examine the effect of the Affordable Care Act (ACA) dependent coverage provision on psychiatric hospital admissions.

Implemented in 2010, the provision requires most private insurers to offer coverage to dependent children of beneficiaries through the child's $26^{\text {th }}$ birthday (if the insurance contract covers dependents). The authors find that the provision increases psychiatric hospital admissions and the use of insurance to pay for treatment with SUD treatment admissions accounting for the largest share. Saloner and Cook (2014) find no effect of the provision on SUD treatment utilization or use of private insurance to pay for treatment among young adults who display need for SUD treatment. Nevertheless, the authors caution that their study may be underpowered to detect significant effects. Finally, Saloner, Antwi, Maclean, and Cook (2017) find that the ACA dependent coverage provision decreases admissions to specialty SUD treatment based on analyses of the Treatment Episode Data Set (TEDS). The authors argue that the provision may allow patients to receive care in other settings such as private doctors’ offices. Moreover, Saloner et al. (2017) find that, following the provision, a greater proportion of patients receiving specialty treatment use private insurance to pay for payment.

Three recent studies investigate the impact of the 2008 Mental Health Parity and Addiction Equity Act (MHPAEA) (Busch et al., 2014; Ettner et al., 2016; McGinty et al., 2015). MHPAEA is a federal legislation that prohibits differences in treatment limits and cost-sharing and expands coverage requirements to SUD treatment for most private and public health

\footnotetext{
${ }^{9}$ However, results are somewhat sensitive to specification. In particular, while differences-in-differences, using geographically similar states as a comparison group, generate a precisely estimated increase in admissions, synthetic control methods generate imprecise findings.
} 
insurance plans that provide coverage for behavioral health (i.e., SUDs and mental health). The results of these studies suggest a modest effect of MHPAEA on SUD treatment utilization overall, but larger expansions in out-of-network service use-which is noteworthy because many networks lack adequate SUD providers—and cost-shifting from patients to insurers.

Finally, some recent research investigates the impacts of state parity laws on SUD treatment outcomes. These studies are most similar to our work as they leverage comparable sources of variation. Dave and Mukerjee (2011) use the TEDS and show that parity laws for behavioral health (both mental health and SUD treatment services) increase the number of SUD treatment admissions and the share of patients using private insurance to pay for payment. Using data drawn from the N-SSATS, Wen et al. (2013) also find that state parity laws increase treatment admissions with larger effects among providers that accept private insurance. Further, Maclean, Popovici, and Stern (2017) also analyze N-SSATS data and show that following passage of a state parity law, providers display an increase in the quantity of SUD treatment admissions and the number of patients in treatment. Similarly, Wen, Hockenberry, and Cummings (2017) document, again using N-SSATS, that parity laws increase SUD treatment rates. $^{10}$

Collectively, these studies imply that parity laws increase SUD treatment utilization. Given that another body of literature has established the effectiveness of numerous modalities of SUD treatment, this research opens the door to the possibility of positive spillover effects from parity laws to traffic fatalities. We test this relationship using FARS data.

\section{Data and methods}

\subsection{Fatality Analysis Reporting System (FARS)}

\footnotetext{
${ }^{10}$ The main focus of the Wen et al (2017) study is Medicaid Health Insurance Accountability waivers on crime; with parity laws serving as a control variable.
} 
Data on fatal crashes occurring on public roads in the U.S. is obtained from the Fatality Analysis Reporting System (FARS) of the National Highway Traffic Safety Administration (NHTSA). These data are widely employed by policy analysts to study the effects of public policies on traffic fatalities (Abouk \& Adams, 2013; Adams, Cotti, \& Tefft, 2015; French \& Gumus, 2015) and by governments of all levels to monitor trends in traffic safety and to develop strategies to reduce fatal crashes (Koehler \& Brown, 2009). FARS data represent the census of police-reported fatal traffic crashes occurring on U.S. public roadways (more specifically, crashes resulting in the death of an involved person within 30 days) within the 50 states and DC.

To construct FARS, administrators collect and combine several state-specific data sources including police reports, driver records, vehicle registration files, state highway department data, medical examiners' reports, toxicology reports, and death certificates. These data are compiled into more than 100 individually-coded data elements that characterize the crash, the vehicles, and the persons involved. We pool FARS data for the period 1988 to 2010. Concerns related to the reliability of data during the initial years of FARS data collection convinced us to avoid using data collected in the 1970s and early 1980s. ${ }^{11}$ Other studies define the analysis period in similar ways (French \& Gumus, 2014). At the upper end of the panel we truncate the analysis sample in 2010 as we wish to focus on a period before implementation of the ACA. Six states (California, Connecticut, DC, New Jersey, Minnesota, and Washington) expanded their Medicaid programs in advance of January $1^{\text {st }}$, 2014, the date at which the core provisions of the ACA went into effect (Sommers, Arntson, Kenney, \& Epstein, 2013). In addition, several other early provisions of the ACA (e.g., the dependent coverage provision in September 2010) were implemented in 2010. By focusing on a period prior to 2010, we are able

\footnotetext{
${ }^{11}$ Based on personal communications between the authors and FARS administrators. More details are available on request from the corresponding author.
} 
to avoid confounding from the ACA, which represents the largest transformation of the U.S. healthcare delivery system since the introduction of Medicare and Medicaid in the 1960s (Oberlander, 2010).

\subsection{State parity laws}

Our source of variation is changes in state parity laws that compel private insurers to provide equal coverage for medical/surgical services and both alcohol and psychoactive drug treatment. $^{12}$ We rely on three sources to construct our parity variables: Robinson, Connolly, Whitter, and Magana (2006), Barry and Sindelar (2007), and Wen et al. (2013). During our study period from 1988 to 2010, 12 states passed a parity law. Maryland was the first state in the U.S. to do so in 1994. In Table 1, we list the states that passed a parity law through 2010 (the last year of our study period) and the effective date.

Table 1 also reports whether states transitioned from no regulation of SUD treatment to parity or from a weaker law (e.g., mandated benefits or mandated offer) to parity. Broadly, mandated benefit laws compel insurers to cover a specified set of services while mandated offer laws require that insured offer coverage of SUD treatment services to beneficiaries. The 'bite' of a parity law will likely vary across states based on the regulation in place prior to passage of the parity law. In other words, transitioning from no law to parity is likely to have larger effects than transitioning from a generous mandated benefit law to parity.

We aggregate the FARS data to the annual level for computational ease. For each law, in the passage year, the indicator is set equal to the fraction of the year for which the law was in

\footnotetext{
12 In previous versions of this manuscript we relied on effective dates provided by the National Council of State Legislatures. However, we detected some errors in the effective dates and hence opted to update our coding to the scheme outlined in the manuscript. We thank Jason Hockenberry and Hefei Wen for kindly sharing updated parity coding with us. More details are available on request from the corresponding author.
} 
effect. Years before passage of the parity law are coded as zero and years after passage are coded as one; e.g., if a law became effective July $1^{\text {st }}$, 2002, we code the law as 0.5 in $2002 .{ }^{13}$

\subsection{Outcome variables}

We construct several measures of traffic fatality counts. The first and most comprehensive outcome measure is overall number of persons killed in traffic crashes within a particular state and year (i.e., total fatalities). Second, alcohol involvement is documented by BAC test results collected from police or coroner reports. As these data contain measurement error and several states do not uniformly collect BAC information (Anderson, Hansen, \& Rees, 2013; Eisenberg, 2003), when BAC information is missing, BAC level is statistically imputed by FARS administrators based on characteristics of the crash and driver (Subramanian, 2002). We use both the pharmacological and imputed information to construct measures for the number of traffic fatalities with alcohol involvement. We employ two thresholds for alcohol-involved crashes: (i) fatalities in crashes in which at least one of the drivers had a BAC level over the legal limit of $0.08 \mathrm{~g} / \mathrm{dL}$; and (ii) fatalities in crashes in which at least one of the drivers had a BAC level above $0.15 \mathrm{~g} / \mathrm{dL}$. We use the latter measure to assess whether the parity effects are stronger at more elevated drinking (i.e., more likely to be associated with SUDs).

Ideally, we would like to analyze the number of fatalities in crashes where at least one of the drivers was under the influence of alcohol and/or psychoactive drugs, but data on psychoactive drug (i.e., substances other than alcohol) involvement is not uniformly collected by states and it is subject to several other limitations. FARS administrators began collecting data pertaining to drug tests in 1991, so we are unable to determine drug-involved fatalities prior to

\footnotetext{
${ }^{13}$ We are unable to identify the exact implementation day for some states (i.e., Connecticut, Delaware, Maine, Maryland, Rhode Island, Vermont, and West Virginia). In these cases, we use January $1^{\text {st }}$ of the implementation year. As a robustness check, instead of January $1^{\text {st }}$, we use the date of July $1^{\text {st }}$ and the results are very similar. These alternative estimates are presented in Supplementary Table 1.
} 
this year. Moreover, coding procedures for drug test results changed in 1993, further limiting the availability and reliability of this measure. Although the majority of drivers are not tested for drugs, the testing rate for fatally injured drivers is likely to be higher than the testing rate for surviving drivers (National Highway Traffic Safety Administration, 2010). In 2009, 63\% of drivers who were fatally injured in crashes were tested for drugs. Further complicating the analysis, testing rates vary widely across states. For example, while Maine did not report any drug testing in 2009, California has a drug testing rate of over $80 \%$. Discrepancies also exist across states in drug testing procedures. Even when drug testing data are collected, quantity or concentration information is rarely recorded — testing positive for drugs does not necessarily imply impairment. Finally, FARS reports the presence of any drug regardless of its legal status, including over-the-counter and prescription drugs. Given these issues related to drug involvement information in FARS, we restrict our analysis to alcohol-involved fatalities. ${ }^{14}$ We note our inability to study psychoactive drug-involved fatalities as a limitation of the study.

Finally, examining fatalities from crashes where all drivers had BAC levels under the legal limit of 0.08 can be misleading for several reasons. First, information on whether these drivers are under the influence of psychoactive drugs is not available. Second, this measure could also capture other types of impaired driving (e.g., sleep deprivation) among those drivers with SUDs (Popovici \& French, 2013a). Indeed, numerous studies document that sleep deprivation is a major cause of traffic crashes (Eoh, Chung, \& Kim, 2005; Hack, Choi, Vijayapalan, Davies, \& Stradling, 2001; Terán-Santos, Jimenez-Gomez, Cordero-Guevara, \& the Cooperative Group Burgos-Santander, 1999).

\footnotetext{
${ }^{14}$ Moreover, critical challenges are associated with the presence of measurement error in the dependent variable, especially in non-linear models such as the Poisson models (outlined in Section 3.5) we estimate here (Bound, Brown, \& Mathiowetz, 2001).
} 


\subsection{Control variables}

Traffic fatalities are undoubtedly influenced by numerous factors apart from state parity laws for SUD treatment. Thus, we control for a broad set of explanatory variables in our regression models. In particular, to mitigate potential omitted variable bias in the estimated coefficients, we include controls that can influence both substance-attributable traffic crashes and the propensity of a state to pass an SUD parity law. To this end, we link data from several other administrative and survey sources to the FARS dataset on state and year.

First, we adjust for the fact that our outcome variables are measured as counts, which are heavily influenced by the size of states. To control for exposure, we follow Dee and Evans (2001) and include the natural logarithm of the state population age 21 and older. We use state population data from National Vital Statistics Mortality Files 1988-2010.

Second, we include four policy variables that proxy for state attitudes toward SUDs generally and impaired driving specifically. These variables are likely to affect the number of traffic fatalities and might also be correlated with parity laws for SUD treatment (French \& Gumus, 2014). (i) State-specific blood alcohol concentration (BAC) limit is the maximum legal BAC level for the operator of a motor vehicle. We include an indicator for a state BAC limit of $0.08 \mathrm{~g} / \mathrm{dL}$ or higher (NHTSA Alcohol-Highway Safety Digest Topics and Alcohol Policy Information System). (ii) An indicator variable for a state-specific administrative license revocation (ALR) law (Anderson et al., 2013). This policy allows law enforcement officials to suspend or revoke the license of a driver who refuses to submit to alcohol testing or fails an alcohol test after a traffic stop or crash. (iii) An indicator variable for a prescription drug monitoring program (PDMP) in the state (Ali, Dowd, Classen, Mutter, \& Novak, 2017). Aimed to deter prescription drug abuse and diversion, PDMPs are electronic databases used to record 
and track the prescribing and dispensing of controlled prescription drugs. (iv) An indicator variable for a state law that permits marijuana use for medical purposes (Sabia \& Nguyen, 2016).

Third, to account for other policy effects, we include the state-specific real excise tax per gallon of beer (in dollars) from the Brewers’ Almanac (The Beer Institute, 2012). We include this variable to proxy for state-specific sentiment toward alcohol and psychoactive drug use. Although the beer tax is an imperfect proxy, other measures (e.g., state-level substance use prevalence rates) are themselves potential outcomes of state parity laws and including such variables in regression models can lead to over-controlling bias. Fourth, we include other statelevel variables that are likely correlated with the number of traffic crashes: the natural logarithm of the number of motor vehicle miles traveled on rural and urban roads per 10,000 population (Federal Highway Administration (FHWA), U.S. Department of Transportation 2011), average daily temperature (degrees Fahrenheit) over the course of a year, and annual precipitation (inches) in the state (French \& Gumus, 2014; Houston \& Richardson, 2008).

Finally, we control for state-by-year average demographic variables (gender, age, race, ethnicity, marital status, education, and family income) from the Annual Social and Economic Supplement to the Current Population Survey (Flood, King, Ruggles, \& Warren, 2015). These variables proxy for state-specific characteristics and attitudes that could predict our outcomes and not captured by other included controls (Maclean, Oney, Marti, \& Sindelar, 2018).

\subsection{Empirical model}

We model the relationships between state parity laws and traffic fatalities using a differences-in-differences framework, as outlined in Equation (1):

$$
Y_{s t}=f\left(\alpha_{0}+\alpha_{P L} P L_{s t}+\alpha_{X}^{\prime} X_{s t}+S_{S}+\tau_{t}+\Omega_{s t}\right),
$$


Where $Y_{s t}$ is a traffic fatality outcome in state $s$ and year $t ; P L_{s t}$ is the parity law indicator in state $s$ and year $t$; $X_{s t}$ is a vector of state demographics and policies outlined in Section 3.4.; and $S_{s}$ and $\tau_{t}$ are vectors of state and year fixed effects. State fixed effects control for timeinvariant state-level factors that affect traffic fatalities and/or passage of parity laws. Year fixed effects account for factors impacting the U.S. as a whole (e.g., nationwide trends in traffic fatalities influenced by national safe-driving campaigns, improvements in vehicle safety that are rolled out across the country). $\Omega_{s t}$ is a vector of state-specific linear time trends (i.e., we interact each state fixed effect with a separate linear time trend that takes on a value of 1 for 1988, 2 for 1989, and so forth) that accounts for state-level time-varying factors (albeit, in a linear manner); $\alpha_{P L}$ and $\alpha_{X}^{\prime}$ are parameters to estimate.

All regressions are unweighted. Histograms of our outcome variables show that these variables are strongly right skewed (analysis presented in Supplementary Figure 1). As these dependent variables are counts, we follow Silva and Tenreyro (2006) and estimate conditional fixed-effects Poisson models controlling for exposure (which we proxy with the natural logarithm of the state population). ${ }^{15}$ For ease of interpretation, we report the estimated incidence rate ratios (IRRs) for our key regressors rather than beta coefficient estimates. IRRs represent the exponentiated coefficients and denote the effect of a unit change in the explanatory variable on the rate of fatalities, while holding everything else constant. An IRR greater than one indicates a positive relationship between the fatality measure and the explanatory variable (e.g., parity law), and an IRR less than 1 represents a negative relationship. We report 95\% confidence

\footnotetext{
${ }^{15}$ We prefer the Poisson model to a negative binomial regression model as the latter model is not robust to model misspecification (Cameron \& Trivedi, 2005).
} 
intervals that account for clustering within states (Bertrand, Duflo, \& Mullainathan, 2004). ${ }^{16}$

Clustering at the state-level addresses the equivalent mean-variance assumption of the Poisson model (Cameron \& Trivedi, 2005; Markowitz \& Cuellar, 2007). Despite this specification choice for the core models, results are robust to alternative specifications (e.g., least squares using fatality rates per 100,000). We discuss findings generated by these alternative models in the robustness checks and extensions section below.

When estimating Equation (1), a critical assumption to generate causal effects is that the outcome variables in the 'treated' and 'comparison' groups would have trended similarly in the absence of parity laws, commonly referred to as 'parallel trends’ (Angrist \& Pischke, 2009). To test the validity of the research design, we estimate regression models using the pre-law period data only as outlined in Equation (2):

$$
Y_{s t}=\gamma_{0}+\gamma_{1}\left(\text { Treat }_{s} * \text { Time }_{r}\right)+\gamma_{2}^{\prime} X_{s t}+\theta_{s}+\tau_{t}+e_{s t}
$$

We use data from the pre-law period only as no states are 'treated' in this period. Therefore this 'uncontaminated' data can provide suggestive evidence on symmetry in trends, post-law, for states that did not pass a law and the missing counterfactual for states that pass a law during our full study period (Antwi, Moriya, \& Simon, 2013). Treat $_{s}$ is an indicator variable for the treatment group (states that pass any parity law) and $\operatorname{Time}_{r}$ is a linear time trend. In these analyses, we first use the full sample and center the data around the law passage year. Thus, the linear time trend variable takes on a value of 0 in the year of passage, 1 in the first-year post-law, -1 in the year prior to the law passage, and so forth. We randomly assign false

\footnotetext{
${ }^{16}$ The FARS includes all states (including DC) in all years; yielding 51 clusters in our analysis dataset. Recent work on clustered data demonstrates that this number of clusters is sufficient to consistently estimate precision measurements (Cameron \& Miller, 2015).
} 
effective dates to states in the comparison group (i.e., states that do not pass a parity law by 2010) and center the data around this false effective date.

We do not include the state-specific linear time trends in Equation (2) as including such variables in a regression model that allows for dynamics (i.e., the interaction between the treatment indicator and the linear time trend) can complicate interpretation of the estimated regression coefficients (Wolfers, 2006). Moreover, these trends would be perfectly collinear with our variable of interest: Treat $_{s} *$ Time $_{r}$. Not being able to reject the null hypothesis that $\gamma_{1}$ is zero provides further support that our FARS data are able to satisfy the parallel trends assumption and, hence, recover causal estimates of parity law effects.

\section{Results}

\subsection{Summary statistics}

Our analysis sample consists of 1,173 state-year observations. Table 2 reports summary statistics for the full sample in the first column and by state (full vs not) parity law in the last two columns. We report traffic fatalities per 100,000. The mean fatality rate across all states and years is 23.52. The mean fatality rate where at least one driver had a BAC greater than 0.08 is 7.98, while the mean fatality rate where at least one driver had a BAC greater than 0.15 is 5.48 . Approximately $7.6 \%$ of state-year observations in our analysis sample have a parity law in place during a particular year. In addition, around $45 \%$ of the state-year observations have a BAC limit of $0.08 \mathrm{~g} / \mathrm{dL}$ or below, 69\% have an ALR law, 33\% have a PDMP, and 10\% have a medical marijuana law. Average state-specific demographics are comparable to the U.S. population.

Examining state-specific characteristics based on whether the state implemented a parity law by the end of our study period, we find that states with a parity law have a lower average 
fatality rate (22.88 versus 23.85 in states without parity), are more likely to have a BAC limit of $0.08 \mathrm{~g} / \mathrm{dL}$ or below and an administrative license revocation (ALR) law, and are less likely to have a PDMP. We conduct non-parametric Kruskal and Wallis (1952) rank-sum tests and find that the majority of control variables have statistically significant differences in median values between states with and without a parity law. These differences imply the need to control for all factors in our regression model. In this analysis, we compare median values over the entire analysis period for the group of states with parity and the group of states without parity. States with parity have implemented these laws at different times during the analysis period (see Table 1) and approximately $22.8 \%$ of all state/year observations in this sub-sample have the parity law in place in a given period.

\subsection{Internal validity of the research design: Parallel trends}

As noted earlier in the manuscript, a critical assumption for differences-in-differences models to recover causal estimates is that, in the absence of parity, the outcome variables would have trended similarly during the post-treatment period for both the treatment and comparison groups. This assumption is not directly testable as treated states did in fact pass a parity law and their counterfactual trend is not observed (i.e., the missing counterfactual), but we can offer suggestive evidence that the trends would have been similar.

Results from regression-based testing of the parallel trends assumption, Equation (2), are reported in Table 3. We estimate the parallel trend models using OLS due to the challenges associated with interpreting an interaction term in a non-linear model (Popovici, Maclean, Hijazi, \& Radakrishnan, 2017). In these analyses, we cannot reject the null hypotheses of parallel trends between the treatment and comparison groups in the pre-treatment period (i.e., we cannot reject 
$\left.\gamma_{1}=0\right)$ in all regressions. These findings support the parallel trends assumption and lend credence to our pursuit of causal estimates.

\subsection{Differences-in-differences regression results}

Table 4 reports selected results from our differences-in-differences analysis of the effects of parity laws on total and alcohol-involved traffic fatalities. All IRR estimates for the parity variables are less than 1 , indicating that parity laws have a negative effect on traffic fatality rates. A parity law is associated with a 5.8\% decrease in the annual rate for total traffic fatalities $(p<0.10)$. When viewing results by BAC level, we find that parity laws have a stronger effect on fatalities involving more severely impaired drivers (i.e., BAC levels exceeding 0.15 ). While parity laws are associated with a $7.1 \%$ decrease in the fatality rate where at least one driver had a BAC greater than 0.08 , they are associated with an $8.6 \%$ reduction in the fatality rate where at least one driver had a BAC above 0.15 . Both estimates are statistically significant at the $5 \%$ level.

\subsection{Policy endogeneity}

A key concern with state-level analyses over time is that the policies we study may be passed by states in part to address problems related to impaired driving among their residents rather than the parity laws leading to changes in traffic fatalities (Besley \& Case, 2000). If true, the coefficients estimated in Equation (1) may be subject to bias from policy endogeneity (i.e., state-level reverse causality).

To explore this possible threat to identification, we conduct an event study in the spirit of Autor (2003). Equation (3) outlines the specification of our event study analysis.

$$
Y_{s t}=f\left(\beta_{0}+\sum_{j=-4}^{4} \delta_{j} P L_{s t}+\beta_{X}^{\prime} X_{s t}+S_{S}+\tau_{t}\right) .
$$


We first center the data around the event (i.e., parity law passage) for states that pass a parity law by 2010. Next, following Kline (2011), we construct an event window that includes the period seven years prior to law passage and seven years after law passage. Imposing such endpoint restrictions implicitly assumes that no anticipatory effects are present more than seven years in advance of the parity law passage and the effects dissipate after seven years. Under this definition, 102 state-year observations are excluded from the event study analysis because they fall outside the event window. We then create bins seven years pre-law, five to six years prelaw, three to four years pre-law, one to two years pre-law, year of law passage, one to two years post-law, three to four years post-law, five to six years post law, and seven years post-law. The omitted (i.e., comparison) period is one to two years pre-law passage. We follow Lovenheim (2009) and code states that do not pass a parity law by 2010 as zero for all bins.

The estimates for the leads can reveal pre-implementation effects (i.e., policy endogeneity), while the estimates for the lags offer insight on whether the effects of parity laws persist beyond the implementation period. We do not include state-specific linear time trends in the event study model as including such trends complicates interpretation of the coefficient estimates in models that allow for dynamics in treatment effects, as is the case in an event study (Wolfers, 2006). All other covariates are the same as those defined for Equation (1).

If we uncover evidence of policy endogeneity (i.e., estimates on the policy leads that are statistically different from zero), controlling for pre-policy leads in the regression model should allow us to isolate the direct effect of parity laws on traffic fatalities. Put differently, once we control for the policy leads, we can minimize concerns regarding bias due to reverse causality in our implementation effects and policy lags. We graphically report results from the event study in Figure 1. Table 5 contains corresponding coefficient estimates and 95\% confidence intervals. 
The event study results are broadly robust to the inclusion of lead and lag indicator variables. Namely, we find no evidence of pre-implementation trends as all estimated IRRs for the leads are non-significant at conventional levels. Moreover, $\chi^{2}$ tests indicate that the estimated IRRs for the lead variables are jointly non-significant (results not reported, but available on request from the corresponding author). However, compared to the results from Equation (1), only the year-of-implementation and 1-2 years post-implementation estimates from Equation (3) are in the same direction (negative) for all fatality measures and only the estimates for 1-2 years post-implementation are statistically significant. This change in precision is perhaps not surprising as we estimate heavily saturated regression models and event studies are known to be 'data hungry.' In general, however, these findings are comparable to our main results in that parity laws are negatively related to traffic fatality rates, but the effects dissipate starting around 3 years post-implementation.

\section{Robustness checks and extensions}

\subsection{SUD outcomes}

Although we are primarily focused on whether private health insurance expansions decrease traffic fatalities through increases in access to and affordability of SUD treatment in our study, it is also prudent to examine whether these expansions decrease SUDs within the general population. Namely, if parity laws do not reduce SUDs then interpreting the effects we identify in FARS is more difficult.

To address this question, we examine the public use National Vital Statistics Mortality Files (NVSM) between 1999 and 2010. Ideally, we would examine NVSM data for our full study period (1988 to 2010). However, an important break in the NVSM data occurred between 1998 and 1999 as data administrators transitioned from International Statistical Classification of 
Diseases and Related Health Problems (ICD) 9 to 10 coding scheme. To the best of our knowledge, no established method exists to crosswalk across these two systems. Hence, we follow the related literature and employ data from 1999 onward for our analyses of parity laws, fatal alcohol poisonings, and psychoactive drug overdoses (Popovici et al., 2017).

NVSM tracks all-cause mortality in the U.S. and thus provides us with the universe of deaths classified as fatal alcohol poisonings and psychoactive drug-related overdoses. Operationally, we construct measures for the total number of deaths in each of these two categories and combined for the population 21-64 years of age. ${ }^{17}$ Moreover, we use the same procedure outlined above for FARS to link effective dates for state parity laws to the NVSM data. ${ }^{18}$ NVSM results are reported in Appendix Table 1.

To summarize, we find evidence that passage of a parity law significantly reduces the number of psychoactive drug-related overdose deaths and the combined (alcohol and psychoactive drug) total number of deaths. The estimate for fatal alcohol poisonings alone is close to 1 and not statistically significant. Quantitatively, a parity law is associated with an $8.8 \%$ decrease in the number of psychoactive drug-related overdose deaths and a $4.9 \%$ decrease in the combined number of fatal alcohol poisonings and psychoactive drug-related overdoses.

\subsection{Changes in insurance composition}

The parity laws we study should increase coverage for SUD treatment services among the privately insured. However, it is possible that, following a parity law and the ensuing increase in coverage for SUD treatment services in private insurance contracts, uninsured or publicly

\footnotetext{
${ }^{17}$ Specifically, we use the public use Underlying Cause of Death files from the Centers for Disease Control and Prevention to determine deaths attributable to alcohol and psychoactive drugs. There were no suppressed cells in the data. More details available on request.

${ }^{18}$ We aggregate the NVSM to the year level. We could have used monthly NVSM data, but monthly data contain a substantial amount of left censoring, which is imposed by the National Center for Health Statistics due to privacy concerns. Thus, we opted to use the annual data to avoid such censoring. More details available on request.
} 
insured individuals with SUDs may opt to take up private coverage to take advantage of the newly covered services (i.e., a form of adverse selection). If such adverse selection occurs postparity law, then the composition of the privately insured may change which opens the door to conditional-on-positive bias (Angrist \& Pischke, 2009). In particular, it may be that post-parity law, any changes in SUD treatment service use and attributable changes in substance-impaired traffic crashes are due to differences in the population of privately insured individuals rather than changes in treatment use and reductions in SUDs attributable parity laws per se. Presumably those individuals who take up private insurance to access SUD benefits have, on average, more severe SUDs than the previously privately insured (i.e., adverse selection). Similarly, some previously insured patients may opt to drop coverage due to increased premiums (Bailey, 2014; Bailey \& Blascak, 2016). Such phenomena can bias regression coefficients. We provide suggestive evidence on such changes in the composition of the insured by regressing the proportion of the state with any insurance, private insurance, and public insurance from the Annual Social and Economic Supplement to the Current Population Survey over the analysis period on parity and state demographics. We note that this analysis considers only the extensive margin of insurance, in particular it does not account for those who switch from one private plan to another post-parity. The regression results suggest that passage of a parity law does not induce changes in overall, private, or public insurance coverage (Appendix Table 2). We interpret these null findings to suggest that conditional-on-positive (i.e., changes in the composition of the privately insured) does not lead to bias in our coefficient estimates.

\subsection{Changes in the number of SUD treatment providers}

Another form of compositional-on-positive bias could occur if the parity laws we study induce some providers to enter or exit the market (Angrist \& Pischke, 2009). To explore 
whether this form of bias is present, we regress the total number of providers from the County Business Patterns from the U.S. Census Bureau on the parity laws and state demographics. The six digit North American Industry Classification System (NAICS) codes replaced the four digit Standard Industrial Classification (SIC) codes in 1998 in the County Business Patterns data. To the best of our knowledge, there is no validated method to crosswalk across the codes. We are using data for the period 1998-2010 and find no statistically significant evidence that state parity laws alter the number of providers (Appendix Table 3). We note that this analysis only considers

specialty SUD treatment providers and does not account for other forms of treatment (e.g., SUD treatment received in private doctors' offices). However, the null findings are in line with the hypothesis that parity law passage does not lead to substantial changes in the population of SUD treatment providers.

\subsection{Other robustness checks}

We explore the stability of our core findings to functional form. We estimate OLS regressions using fatality rates per 100,000 population aged 21 years and older (Appendix Table 4) and the natural logarithm of fatality rates per 100,000 population aged 21 years and older population (Appendix Table 5). The negative estimates suggest parity laws are associated with decreases in all fatality measures. Nevertheless, when compared to estimates from the Poisson models, they are not as precise. We suspect that the Poisson is better fit to the data and hence affords us additional precision. Finally, we lag the parity law variable by one year to allow for a time delay between the implementation of a law and the traffic fatality measures we study (Appendix Table 6). The results are consistent with the results of the core models. As expected, the estimates reach higher levels of statistical significance.

\section{Discussion and conclusion}


The primary objective of this study is to determine whether state parity laws, that is laws that compel private insurers to provide equal coverage for substance use disorder (SUD) treatment vis-à-vis medical/surgical treatment, have positive spillover effects on fatal traffic crashes. We hypothesize that an increase in the number of substance users seeking SUD treatment because of parity legislation will reduce the number of impaired drivers on roadways and, consequently, decrease the number of traffic fatalities.

Our main finding supports this hypothesis as state-specific traffic fatalities decline after passage of a parity law. However, we identify heterogeneity in impacts, especially pertaining to BAC levels of the drivers. In line with the premise that alcohol involvement in crashes decreases when parity laws are in place, we find a dose-response relationship between parity laws and traffic fatalities - the effect size increases with the BAC level of the drivers. We also find evidence that parity laws reduce the number of psychoactive drug-related overdoses and the combined number of fatal alcohol poisonings and psychoactive drug-related overdoses within the adult population (the population most likely to be affected by state parity laws).

Given that our analysis estimates the effect of parity laws on traffic fatalities rather than a 'first stage' effect on SUDs, it is important to determine whether the magnitude of the estimates is reasonable. One way to examine plausibility is to consider the extent to which private insurance is used to pay for SUD treatment services. While private insurance has historically played a more modest role in the financing of SUD treatment compared to medical/surgical services, this differential does not imply that private insurance is an unimportant source of financing within the SUD treatment system. Indeed, data from the National Survey of Drug Use and Health (NSDUH) reveals that in 2010, our last analysis period year, 36.9\% of patients receiving SUD treatment used private health insurance as a source of payment for their last 
treatment episode (Substance Abuse and Mental Health Services Administration, 2011). This value may understate the true penetration of private insurance in the financing of SUD treatment as the estimate only captures the use of private insurance for the last service episode. For example, individuals who receive SUD treatment multiple times within a year and use private insurance to pay for more distal treatment episodes would not be included in this percentage. Finally, given that numerous studies in the clinical and health services research literatures establishing the effectiveness of different modalities of SUD treatment (McLellan, Lewis, O'brien, \& Kleber, 2000), we expect that many of the additional patients who are receiving SUD treatment due to parity are less likely to use substances and drive while impaired.

Another approach to gauge whether or not the magnitudes of our estimated effect sizes are reasonable is to consider the share of the population that is impacted by state parity laws. According to Jensen and Morrisey (1999), 33 to 43\% of the U.S. population is impacted by a private health insurance expansion. Wen et al. (2013) report that passage of a state parity law leads to a 9\% increase in admissions to specialty SUD treatment facilities, and Maclean et al. (2017) document a similar increase in admissions. While none of these estimates are definitive, they collectively suggest that parity legislation can have an important effect on private insurance markets and the use of private insurance to pay for SUD treatment, thereby supporting the validity of our DD estimates for traffic fatalities.

An additional argument to defend the reasonableness of the effect sizes is that state parity laws could affect both the extensive and intensive margins of SUD treatment. We have focused our proposed mechanisms on the extensive margin of treatment, but the relationships between parity laws and traffic fatalities could also work through the intensive margin. Namely, while some individuals will gain insurance coverage for SUD treatment through parity legislation, 
others may experience an increase in the generosity of their current plan. For example, in the pre-parity period, an insured individual may have had coverage for a basic set of heavily restricted services (e.g., pre-authorization, stepped therapy, high cost-sharing, limited number of allowable annual/lifetime episodes of care). After passage of a parity policy, these restrictions may be loosened or eliminated. This hypothesis is supported by McGinty et al. (2015) who show that MHPAEA increased use of out-of-network services, which may reflect expanded access to SUD treatment providers for beneficiaries. Although individuals acting in this way would have been designated as having coverage for SUD treatment pre-parity, the coverage may not have adequately met his/her treatment needs in terms of either service availability or intensity. Thus, increased insurance generosity because of parity legislation may now allow some individuals to obtain more comprehensive SUD treatment (e.g., treatment that addresses overall patient health, relies on the use of both counseling and medications, and is of sufficient duration with appropriate follow up care rather than detoxification services only that simply allow the body to expel substances) and/or treatment that is better matched to patient needs. While we cannot observe or measure such coverage gains in our data, it is conceivable that these gains, if present, would facilitate more comprehensive and effective SUD treatment, and thereby reduce both SUD prevalence and fatal traffic crashes.

Our study has several limitations. (i) We are unable to obtain data on non-fatal traffic crashes, those that are not reported to the police, or crashes that occur on private roadways. Clearly, non-fatal traffic injuries are more common and result in greater healthcare expenditures compared to fatal traffic crashes. We encourage future work, using state and local data sets, on this important question and view our study as a first step in understanding the SUD parity law/traffic safety relationship. (ii) While we have information on alcohol-involved and alcohol- 
impaired traffic fatalities, we lack data on traffic fatalities involving other drugs due to reporting issues in FARS. This would be another fruitful area of exploration for future research. (iii) Although parity laws might impact the number of substance users seeking treatment and hence the rates of untreated SUDs in the population, our data on fatal alcohol poisonings and psychoactive drug-related overdoses are proxies for direct clinical measures of adult SUDs. (iv) While FARS data provide the specific dates on which particular crashes occur, the implementation date of 7 out of 12 state parity laws is unavailable. Hence, we are not able to more accurately match parity laws to specific accident dates in FARS. We note the inability to more accurately match laws to the FARS as a limitation of the study.

Despite these limitations, our findings are timely and policy relevant for several reasons. First, they document the public health value of mandating that private insurers offer an equitable and affordable level of healthcare coverage, thus contributing to the broader public policy debate on this topic. Second, the ACA in conjunction with MHPAEA requires that most private health insurance plans on state and federal exchanges, as well as many public plans, offer SUD treatment at parity with medical/surgical benefits. Our findings suggest that these two Acts, via their parity provisions, may reduce the number of impaired drivers, thereby improving overall traffic safety. Recent uncertainty surrounding the political fate of the ACA—-the Trump Administration and Republican Congress have a long-standing objective of repealing this Actparticularly the essential health benefit package (which includes SUD treatment), the state Medicaid expansions, and the guaranteed coverage issue, magnifies the significance of these research findings as they can inform policymakers on the benefits of expanding SUD treatment availability. Third, these findings contribute to the growing literature on the clinical and 
economic benefits of SUD treatment, and reveal that such services can lead to significant social welfare gains that extend beyond the affected individual.

In conclusion, traffic safety is a major public health issue and fatal traffic crashes are a leading cause of death in the U.S. Many current policies adopt a punitive approach to reducing substance-related traffic crashes (e.g., legal consequences associated with DUI that involve financial payment, license restrictions, community service, and/or incarceration) or simply provide basic information about the dangers of driving under the influence of substances (e.g., media campaigns). Despite the implementation of these and other traffic policies, rates of substance-involved traffic fatalities remain alarmingly high—adults reported driving after drinking 112 million times in 2010 (Centers for Disease Control and Prevention, 2015b). Our research suggests that policy makers could consider the indirect benefits of ancillary policies such as health insurance parity laws as a viable and effective approach to enhance traffic safety. 
Table 1. States that passed a parity law during study period: 1988-2010

\begin{tabular}{l|l|l}
\hline \hline State & Effective date & Parity law transition \\
\hline Arkansas & October 2009 & Mandated offer to parity \\
Connecticut & 2000 (no month) & None to parity \\
Delaware & 2001 (no month) & None to parity \\
Kansas & July 2009 & Mandated benefits to parity \\
Louisiana & January 2009 & Mandated benefits to parity \\
Maine & 2003 (no month) & Mandated benefits to parity \\
Maryland & 1994 (no month) & None to parity \\
Oregon & July 2007 & Mandated benefits to parity \\
Rhode Island & 2002 (no month) & Mandated benefits to parity \\
Texas & April, 2005 & Mandated benefits to parity \\
Vermont & 1998 (no month) & None to parity \\
West Virginia & 2004 (no month) & None to parity \\
\hline
\end{tabular}

Notes: See text for details on parity law sources. Mandated offer = private insurers are compelled to offer coverage for SUD treatment to beneficiaries; this coverage may be at parity with medical/surgery services benefits or not. Mandated benefits = private insurers are compelled to cover a set of SUD treatment services; the covered services, limits on service use, and cost-sharing arrangements may be less generous than those offered for medical/surgical services. 
Table 2. Descriptive statistics for the full sample and by type of parity law, FARS 1988-2010

\begin{tabular}{|c|c|c|c|}
\hline Variables & $\begin{array}{c}\text { All } \\
\text { states }\end{array}$ & $\begin{array}{c}\text { States } \\
\text { with parity }\end{array}$ & $\begin{array}{l}\text { States without } \\
\text { parity }\end{array}$ \\
\hline \multicolumn{4}{|l|}{ Traffic fatality rates per 100,000 population } \\
\hline Total fatalities & 23.52 & 22.88 & 23.85 \\
\hline BAC $>=0.08$ fatalities $^{1}$ & 7.98 & 7.92 & 8.02 \\
\hline BAC $>=0.15$ fatalities $^{2}$ & 5.48 & 5.42 & 5.51 \\
\hline \multicolumn{4}{|l|}{ Parity law } \\
\hline Parity & 0.076 & 0.228 & 0 \\
\hline \multicolumn{4}{|l|}{$\begin{array}{l}\text { Demographics and other state } \\
\text { characteristics }\end{array}$} \\
\hline Age $^{* * *}$ & 46.28 & 46.66 & 46.09 \\
\hline Female** & 0.529 & 0.530 & 0.528 \\
\hline Male** & 0.471 & 0.470 & 0.472 \\
\hline White*** & 0.838 & 0.881 & 0.816 \\
\hline African American*** & 0.102 & 0.085 & 0.110 \\
\hline Other race $* * *$ & 0.061 & 0.034 & 0.074 \\
\hline Hispanic*** & 0.088 & 0.063 & 0.101 \\
\hline Married & 0.631 & 0.635 & 0.629 \\
\hline Divorced, separated, or widowed*** & 0.194 & 0.198 & 0.192 \\
\hline Never married*** & 0.175 & 0.167 & 0.179 \\
\hline Less than high-school education & 0.208 & 0.210 & 0.207 \\
\hline High-school diploma or equivalent*** & 0.292 & 0.301 & 0.287 \\
\hline Some college but no degree ${ }^{* * *}$ & 0.275 & 0.263 & 0.281 \\
\hline College degree & 0.225 & 0.225 & 0.225 \\
\hline Annual family income & 54,583 & 54,210 & 54,770 \\
\hline $\begin{array}{l}\text { Ln(urban vehicle miles traveled per } 10,000 \\
\text { people)*** }\end{array}$ & 4.252 & 4.170 & 4.294 \\
\hline $\begin{array}{l}\text { Ln(rural vehicle miles traveled per 10,000 } \\
\text { people)*** }\end{array}$ & 4.085 & 4.120 & 4.068 \\
\hline BAC limit $<=0.08^{*}$ & 0.448 & 0.483 & 0.430 \\
\hline Administrative license revocation policy & 0.690 & 0.703 & 0.683 \\
\hline Prescription drug monitoring program & 0.333 & 0.284 & 0.358 \\
\hline Medical marijuana law & 0.097 & 0.110 & 0.091 \\
\hline Beer excise tax (real \$ per gallon)***,† & 0.239 & 0.184 & 0.266 \\
\hline Average annual temperature (degrees $\mathrm{F}$ )*** & 55.23 & 54.01 & 55.84 \\
\hline Average annual precipitation (inches)*** & 35.66 & 40.04 & 33.47 \\
\hline Observations & 1,173 & 391 & 782 \\
\hline
\end{tabular}

${ }^{1}$ At least one driver involved in the crash had a BAC of 0.08 or more.

${ }^{2}$ At least one driver involved in the crash had a BAC of 0.15 or more.

Notes; The unit of observation is a state/year.

${ }^{\dagger}$ In 2010 dollars.

***Statistically significant difference in variable medians across the parity type categories, $p<0.01$, Kruskal-Wallis (1952) equality of populations rank test.

**Statistically significant difference in variable medians across the parity type categories, $p<0.05$, Kruskal-Wallis (1952) equality of populations rank test.

*Statistically significant difference in variable medians across the parity type categories, $p<0.10$, Kruskal-Wallis (1952) equality of populations rank test. 
Table 3. Parallel trends test in pre-treatment period for effects of state parity laws for SUD treatment on traffic fatalities, FARS 1988-2010

\begin{tabular}{lccr}
\hline \hline Outcome: & $\begin{array}{c}\text { Total } \\
\text { fatalities }\end{array}$ & $\begin{array}{c}\text { BAC }>= \\
\mathbf{0 . 0 8} \text { fatalities }^{\mathbf{1}}\end{array}$ & $\begin{array}{c}\text { BAC }>= \\
\mathbf{0 . 1 5}_{\text {fatalities }}{ }^{2}\end{array}$ \\
\hline Sample mean & 23.52 & 7.98 & 5.48 \\
\hline Parity law & 0.095 & -0.014 & -0.006 \\
& {$[-0.061,0.251]$} & {$[-0.064,0.036]$} & {$[-0.039,0.028]$} \\
\hline Observations & $\mathbf{6 8 2}$ & $\mathbf{6 8 2}$ & $\mathbf{6 8 2}$ \\
\hline
\end{tabular}

${ }^{1}$ At least one driver involved in the crash had a BAC of 0.08 or more.

${ }^{2}$ At least one driver involved in the crash had a BAC of 0.15 or more.

Notes: The dependent variable in each specification is the state-specific annual rate per 100,000 population of the respective fatality. Unit of observation is a state/year. All models are estimated with OLS and control for state demographics for population ages $21+$ (age, gender, race/ethnicity, marital status, education, and family income), average annual temperature and precipitation, administrative license revocation policy, BAC limit $<=0.08$, prescription drug monitoring program, medical marijuana law, beer excise taxes, natural logarithm of per capita vehicle miles traveled on rural and urban roads, state and year fixed effects. Observations are weighted by the state population. 95\% confidence intervals account for clustering within states and are reported in square brackets. ***; **; * = statistically different from zero at the1\%; 5\%; $10 \%$ levels. 
Table 4. Effects of state parity laws for SUD treatment on traffic fatalities, FARS 1988-2010

\begin{tabular}{lccc}
\hline & $\begin{array}{c}\text { Total } \\
\text { fatalities }\end{array}$ & $\begin{array}{c}\text { BAC }>= \\
\mathbf{0 . 0 8} \text { fatalities }^{\mathbf{1}}\end{array}$ & $\begin{array}{c}\text { BAC }>= \\
\mathbf{0 . 1 5}_{\text {fatalities }}{ }^{\mathbf{1}}\end{array}$ \\
\hline $\begin{array}{l}\text { Sample mean for } \\
\text { dependent variable }\end{array}$ & 23.52 & 7.98 & 5.48 \\
\hline Parity law & & $0.929^{* *}$ & $0.914^{* *}$ \\
& $0.942^{*}$ & {$[0.867,0.995]$} & {$[0.848,0.985]$} \\
\hline Observations & {$[0.878,1.010]$} & $\mathbf{1 , 1 7 3}$ & $\mathbf{1 , 1 7 3}$ \\
\hline
\end{tabular}

${ }^{1}$ At least one driver involved in the crash had a BAC of 0.08 or more.

${ }^{2}$ At least one driver involved in the crash had a BAC of 0.15 or more.

Notes: The dependent variable in each specification is the state-specific annual count of the respective fatality type. Unit of observation is a state/year. All models are estimated with Poisson regression and controls include logarithm of state population age $21+$, state demographics for population ages 21+ (age, gender, race/ethnicity, marital status, education, and family income), average annual temperature and precipitation, administrative license revocation policy, BAC limit <=0.08, prescription drug monitoring program, medical marijuana law, beer excise tax, natural logarithm of per capita vehicle miles traveled on rural and urban roads, state and year fixed effects, and statespecific time trends. Incidence rate ratios are reported. 95\% confidence intervals account for clustering within states and are reported in square brackets.

$* * * ; * * ; *=$ statistically different from one at the $1 \% ; 5 \% ; 10 \%$ levels. 
Table 5. Effects of state parity laws for SUD treatment on traffic fatalities using an event study model, FARS 1988-2010

\begin{tabular}{lccc}
\hline \hline Outcome: & $\begin{array}{c}\text { Total } \\
\text { fatalities }\end{array}$ & $\begin{array}{c}\text { BAC }>= \\
\mathbf{0 . 0 8} \text { fatalities }^{\mathbf{1}}\end{array}$ & $\begin{array}{c}\text { BAC }>= \\
\mathbf{0 . 1 5}_{\text {fatalities }} \mathbf{2}^{-}\end{array}$ \\
\hline Sample mean & 23.52 & 7.98 & 5.48 \\
\hline 7 years pre- & 0.971 & 1.022 & 0.986 \\
implementation & {$[0.914,1.031]$} & {$[0.940,1.111]$} & {$[0.911,1.068]$} \\
5-6 years pre- & 0.981 & 1.010 & 1.014 \\
implementation & {$[0.946,1.017]$} & {$[0.962,1.060]$} & {$[0.972,1.058]$} \\
3-4 years pre- & 0.989 & 0.991 & 0.979 \\
implementation & {$[0.945,1.034]$} & {$[0.924,1.063]$} & {$[0.923,1.039]$} \\
Implementation & 0.979 & 0.964 & 0.972 \\
year & {$[0.925,1.036]$} & {$[0.889,1.045]$} & {$[0.868,1.089]$} \\
1-2 years post- & $0.954 * *$ & 0.962 & $0.928 * *$ \\
implementation & {$[0.920,0.991]$} & {$[0.900,1.028]$} & {$[0.872,0.987]$} \\
3-4 years post- & 0.997 & 1.014 & 1.001 \\
implementation & {$[0.960,1.036]$} & {$[0.955,1.077]$} & {$[0.946,1.059]$} \\
5-6 years post- & 0.978 & 1.021 & 1.008 \\
implementation & {$[0.936,1.020]$} & {$[0.904,1.152]$} & {$[0.908,1.119]$} \\
7 years post- & 1.019 & $1.082 *$ & 1.008 \\
implementation & {$[0.948,1.095]$} & {$[0.993,1.180]$} & {$[0.913,1.112]$} \\
\hline Observations & $\mathbf{1 , 0 7 1}$ & $\mathbf{1 , 0 7 1}$ & $\mathbf{1 , 0 7 1}$ \\
\hline
\end{tabular}

Notes: The dependent variable in each specification is the annual state-specific count of the respective fatality type. Unit of observation is a state/year. Omitted category is 1-2 years prior to the law passage. The event window is -7 to +7 . Observations outside the event window are excluded. States that do not pass a parity law by 2010 are coded as 0 for all bins. All models are estimated with a Poisson model and control for natural logarithm of state population age $21+$, state demographics for population ages 21+ (age, gender, race/ethnicity, marital status, education, and family income), average annual temperature and precipitation, administrative license revocation policy, BAC limit $<=0.08$, prescription drug monitoring program, medical marijuana law, beer excise taxes, natural logarithm of per capita vehicle miles traveled on rural and urban roads, state and year fixed effects. Incidence rate ratios are reported. 95\% confidence intervals account for clustering within states and are reported in square brackets. $* * * ; * * ; *=$ statistically different from one at the $1 \% ; 5 \% ; 10 \%$ levels. 
Appendix Table 1. Effects of state parity laws for SUD treatment on alcohol poisoning and drug overdose deaths, NVSM 1999-2010

\begin{tabular}{|c|c|c|c|}
\hline Outcome: & $\begin{array}{c}\text { Fatal alcohol } \\
\text { poisoning deaths }\end{array}$ & $\begin{array}{c}\text { Drug overdose } \\
\text { deaths }\end{array}$ & $\begin{array}{c}\text { Total number of } \\
\text { deaths }\end{array}$ \\
\hline Sample mean & 342 & 573 & \\
\hline Parity law & $\begin{array}{c}1.009 \\
{[0.971-1.048]}\end{array}$ & $\begin{array}{c}0.912 * * \\
{[0.846-0.982]}\end{array}$ & $\begin{array}{c}0.951 * \\
{[0.903-1.002]}\end{array}$ \\
\hline Observations & 612 & 611 & 611 \\
\hline \multicolumn{4}{|c|}{$\begin{array}{l}\text { Notes: Unit of observation is a state/year. All models are estimated with a Poisson model and control for logarithm } \\
\text { of state population age } 21+\text {, state demographics for population ages } 21+\text { (age, gender, race/ethnicity, marital status, } \\
\text { education, and family income), administrative license revocation policy, BAC limit }<=0.08 \text {, prescription drug } \\
\text { monitoring program, medical marijuana law, beer excise tax, state and year fixed effects. Incidence rate ratios are } \\
\text { reported. } 95 \% \text { confidence intervals account for clustering within states and are reported in square brackets. Sample } \\
\text { sizes vary due to missing alcohol misuse data. } \\
* * * ; * * ; * \text { statistically different from zero at the } 1 \% ; 5 \% ; 10 \% \text { levels. }\end{array}$} \\
\hline
\end{tabular}


Appendix Table 2. Effects of state parity laws for SUD treatment on insurance status, Annual Social and Economic Supplement to the Current Population Survey, 1988-2010

\begin{tabular}{lccc}
\hline \hline Outcome: & Any insurance & Private insurance & Public insurance \\
\hline Sample mean & 0.838 & 0.750 & 0.127 \\
\hline Parity law & 0.000 & 0.002 & -0.000 \\
& {$[-0.008,0.009]$} & {$[-0.012,0.016]$} & {$[-0.014,0.013]$} \\
\hline Observations & $\mathbf{1 , 1 7 3}$ & $\mathbf{1 , 1 7 3}$ & $\mathbf{1 , 1 7 3}$ \\
\hline
\end{tabular}

Notes: All models are estimated with OLS regression and controls include state population age 21+, state demographics for population ages 21+ (age, gender, race/ethnicity, marital status, education, and family income), average annual temperature and precipitation, administrative license revocation policy, BAC limit $<=0.08$, prescription drug monitoring program, medical marijuana law, real beer excise taxes, natural logarithm of per capita vehicle miles traveled on rural and urban roads, state and year fixed effects, and state-specific linear time trends. $95 \%$ confidence intervals account for clustering within states and are reported in square brackets.

***; **; * = statistically different from one at the $1 \% ; 5 \%$; $10 \%$ levels. 
Appendix Table 3. Effects of state parity laws for SUD treatment on the number of facilities, County Business Patterns, 1988-2010

\begin{tabular}{lc}
\hline \hline Outcome: & Total facilities \\
\hline Sample mean & 291.4 \\
\hline Parity law & -27.81 \\
& {$[-83.30,27.69]$} \\
\hline Observations & $\mathbf{6 6 3}$ \\
\hline
\end{tabular}

Notes: All models are estimated with OLS regression and controls include state population age 21+, state demographics for population ages 21+ (age, gender, race/ethnicity, marital status, education, and family income), average annual temperature and precipitation, administrative license revocation policy, BAC limit $<=0.08$, prescription drug monitoring program, medical marijuana law, real beer excise taxes, natural logarithm of per capita vehicle miles traveled on rural and urban roads, state and year fixed effects, and state-specific linear time trends. $95 \%$ confidence intervals account for clustering within states and are reported in square brackets.

***; **; * = statistically different from one at the $1 \% ; 5 \%$; $10 \%$ levels. 
Appendix Table 4. Effects of state parity laws for SUD treatment on traffic fatalities using a linear model, FARS 1988-2010

\begin{tabular}{lccc}
\hline \hline Outcome: & $\begin{array}{c}\text { Total } \\
\text { fatalities }\end{array}$ & $\begin{array}{c}\text { BAC }>= \\
\mathbf{0 . 0 8} \text { fatalities }\end{array}$ & $\begin{array}{c}\text { BAC }>= \\
\mathbf{0 . 1 5} \text { fatalities }\end{array}$ \\
\hline Sample mean & 23.52 & 7.98 & 5.48 \\
\hline Parity law & $-1.707^{*}$ & -0.415 & -0.300 \\
& {$[-3.415,0.002]$} & {$[-1.044,0.215]$} & {$[-0.754,0.153]$} \\
\hline Observations & $\mathbf{1 , 1 7 3}$ & $\mathbf{1 , 1 7 3}$ & $\mathbf{1 , 1 7 3}$ \\
\hline
\end{tabular}

Notes: The dependent variable in each specification is the state-specific annual rate per 100,000 population of the respective fatality. Unit of observation is a state/year. All models estimated with OLS and control for state demographics for population ages $21+$ (age, gender, race/ethnicity, marital status, education, and family income), average annual temperature and precipitation, administrative license revocation policy, BAC limit $<=0.08$, prescription drug monitoring program, medical marijuana law, real beer excise taxes, natural logarithm of vehicle miles traveled on rural and urban roads per capita, state and year fixed effects, and state-specific time trends.

Observations are weighted by the state population. 95\% confidence intervals account for clustering within states and are reported in square brackets.

***; **; * = statistically different from one at the1\%; 5\%; $10 \%$ levels. 
Appendix Table 5. Effects of state parity laws for SUD treatment on the natural logarithm of traffic fatalities using a linear model, FARS 1988-2010

\begin{tabular}{lccc}
\hline \hline Outcome: & $\begin{array}{c}\text { Total } \\
\text { fatalities }\end{array}$ & $\begin{array}{c}\text { BAC }>= \\
\mathbf{0 . 0 8} \text { fatalities }\end{array}$ & $\begin{array}{c}\text { BAC }>= \\
\mathbf{0 . 1 5} \text { fatalities }\end{array}$ \\
\hline Sample mean & 23.52 & 7.98 & 5.48 \\
\hline Parity law & -0.052 & $-0.059^{*}$ & $-0.074^{* *}$ \\
& {$[-0.118,0.014]$} & {$[-0.128,0.010]$} & {$[-0.147,-0.001]$} \\
\hline Observations & $\mathbf{1 , 1 7 3}$ & $\mathbf{1 , 1 7 3}$ & $\mathbf{1 , 1 7 3}$ \\
\hline
\end{tabular}

Notes: The dependent variable in each specification is the state-specific annual rate per 100,000 population of the respective fatality. Unit of observation is a state/year. All models estimated with OLS and control for state demographics for population ages 21+ (age, gender, race/ethnicity, marital status, education, and family income), average annual temperature and precipitation, administrative license revocation policy, BAC limit $<=0.08$, prescription drug monitoring program, medical marijuana law, real beer excise taxes, natural logarithm of vehicle miles traveled on rural and urban roads per capita, state and year fixed effects, and state-specific time trends.

Observations are weighted by the state population. 95\% confidence intervals account for clustering within states and are reported in square brackets.

***; **; * = statistically different from one at the $1 \% ; 5 \% ; 10 \%$ levels. 
Appendix Table 6. Effects of state lagged parity laws for SUD treatment on traffic fatalities, FARS 1988-2010

\begin{tabular}{lccc}
\hline \hline & $\begin{array}{c}\text { Total } \\
\text { fatalities }\end{array}$ & $\begin{array}{c}\text { BAC }>= \\
\mathbf{0 . 0 8} \text { fatalities }^{\mathbf{1}}\end{array}$ & $\begin{array}{c}\text { BAC }>= \\
\mathbf{0 . 1 5} \text { fatalities }^{2}\end{array}$ \\
\hline $\begin{array}{l}\text { Sample mean for } \\
\text { dependent variable }\end{array}$ & 23.52 & 7.98 & 5.48 \\
\hline Parity law (lagged) & & $0.937 * * *$ & $0.914^{* * *}$ \\
& $0.941^{* * *}$ & {$[0.896,0.980]$} & {$[0.866,0.963]$} \\
\hline Observations & {$[0.907,0.977]$} & $\mathbf{1 , 1 7 3}$ & $\mathbf{1 , 1 7 3}$ \\
\hline
\end{tabular}

${ }^{1}$ At least one driver involved in the crash had a BAC of 0.08 or more.

${ }^{2}$ At least one driver involved in the crash had a BAC of 0.15 or more.

Notes: The dependent variable in each specification is the state-specific annual count of the respective fatality type. Unit of observation is a state/year. All models are estimated with Poisson regression and controls include logarithm of state population age $21+$, state demographics for population ages 21+ (age, gender, race/ethnicity, marital status, education, and family income), average annual temperature and precipitation, administrative license revocation policy, BAC limit <=0.08, prescription drug monitoring program, medical marijuana law, beer excise tax, natural logarithm of per capita vehicle miles traveled on rural and urban roads, state and year fixed effects, and statespecific time trends. Incidence rate ratios are reported. 95\% confidence intervals account for clustering within states and are reported in square brackets.

$* * * ; * * ; *=$ statistically different from one at the $1 \% ; 5 \% ; 10 \%$ levels. 
Figure 1. Effect of state parity laws for SUD treatment on traffic fatalities using an event study, FARS 19882010

Total Fatalities

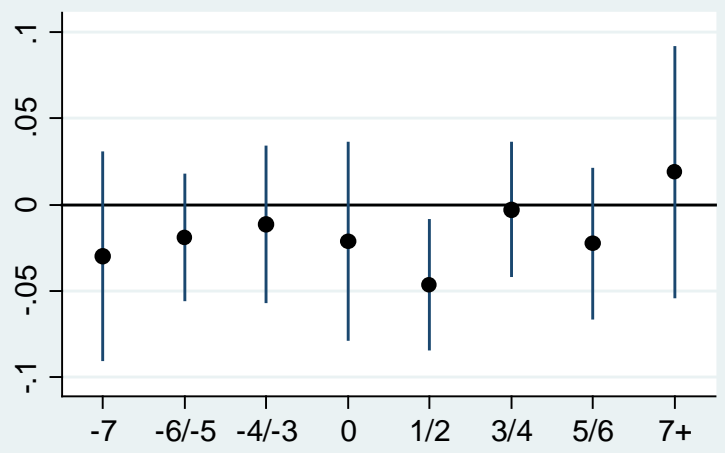

BAC $>=0.15$ fatalities

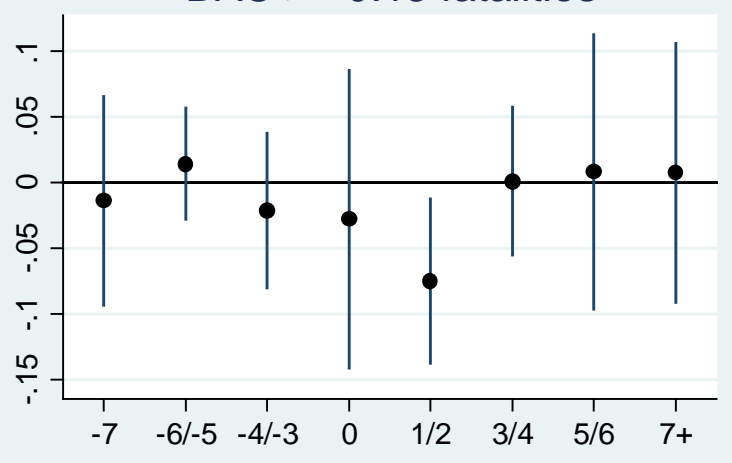

BAC $>=0.08$ fatalities

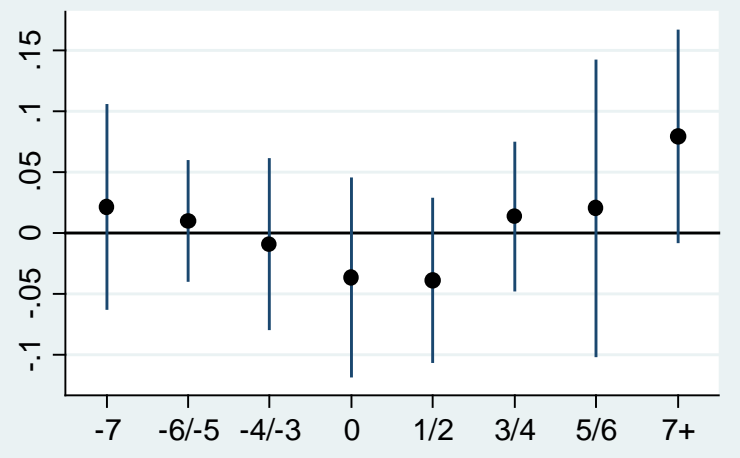

Notes: Unit of observation is a state/year. Event study includes three leads (binary indicators for 7 years, 5 to 6 years, and 3 to 4 years prior to implementation), four lags (binary indicators for 1 to 2 years, 3 to 4 years, 5 to 6 years post-implementation and 7 years post-implementation), and an indicator for the policy implementation year. Omitted category is $1-2$ years prior to the law passage. The event window is -7 to +7 . Observations outside the event window are excluded. States that do not pass a parity law by 2010 are coded as 0 for all bins. All models are estimated with Poisson regression and control for natural logarithm of state population age 21+, state demographics for population ages $21+$ (age, gender, race/ethnicity, marital status, education, and family income), average annual temperature and precipitation, administrative license revocation policy, BAC limit $<=0.08$, prescription drug monitoring program, medical marijuana law, real beer excise taxes, natural logarithm of per capita vehicle miles traveled on rural and urban roads, state and year fixed effects. 95\% confidence intervals account for state-level clustering and are reported in vertical bars. See Table 4 for coefficient estimates. 
Supplementary Table 1. Effects of state parity laws for SUD treatment on traffic fatalities assigning the date of July $1^{\text {st }}$ of the implementation year for states with unavailable implementation dates, FARS 1988-2010

\begin{tabular}{lccc}
\hline \hline Outcome: & $\begin{array}{c}\text { Total } \\
\text { fatalities }\end{array}$ & $\begin{array}{c}\text { BAC }>= \\
\mathbf{0 . 0 8} \text { fatalities }^{\mathbf{1}}\end{array}$ & $\begin{array}{c}\text { BAC }>= \\
\mathbf{0 . 1 5} \text { fatalities }^{2}\end{array}$ \\
\hline Sample mean & 23.52 & 7.98 & 5.48 \\
\hline Parity law & $0.935^{*}$ & $0.923^{* *}$ & $0.903^{* * *}$ \\
& {$[0.873,1.001]$} & {$[0.862,0.988]$} & {$[0.841,0.971]$} \\
\hline Observations & $\mathbf{1 , 1 7 3}$ & $\mathbf{1 , 1 7 3}$ & $\mathbf{1 , 1 7 3}$ \\
\hline
\end{tabular}

${ }^{1}$ At least one driver involved in the crash had a BAC of 0.08 or more.

${ }^{2}$ At least one driver involved in the crash had a BAC of 0.15 or more.

Notes: The dependent variable in each specification is the state-specific annual count of the respective fatality type. Unit of observation is a state/year. All models are estimated with Poisson regression and controls include logarithm of state population age 21+, state demographics for population ages 21+ (age, gender, race/ethnicity, marital status, education, and family income), average temperature and precipitation, administrative license revocation law, BAC limit $<=0.08$, prescription drug monitoring program, medical marijuana law, beer excise tax, natural logarithm of per capita vehicle miles traveled on rural and urban roads, state and year fixed effects, and state-specific time trends. Incidence rate ratios are reported. 95\% confidence intervals account for clustering within states and are reported in square brackets.

$* * * ; * * ; *=$ statistically different from one at the $1 \% ; 5 \% ; 10 \%$ levels. 
Supplementary Figure 1. Histograms of traffic fatalities measures, FARS 1988-2010
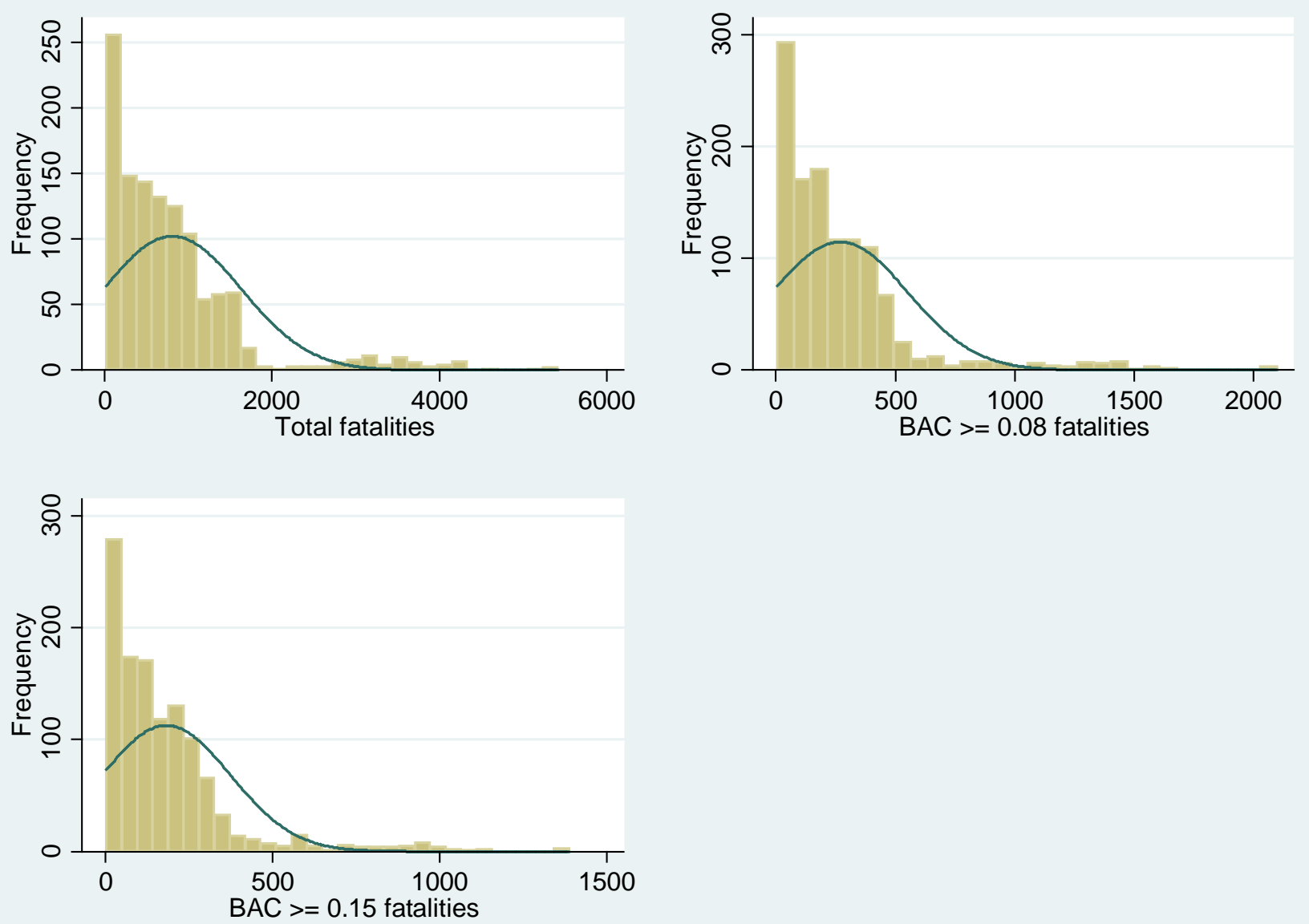


\section{References}

Abouk, R., \& Adams, S. (2013). Texting bans and fatal accidents on roadways: Do they work? Or do drivers just react to announcements of bans? American Economic Journal: Applied Economics, 5, 179-199.

Adams, S., Cotti, C., \& Tefft, N. (2015). Seatbelt use among drunk drivers in different legislative settings. Economic Inquiry, 53, 758-772.

Ali, M. M., Dowd, W. N., Classen, T., Mutter, R., \& Novak, S. P. (2017). Prescription drug monitoring programs, nonmedical use of prescription drugs, and heroin use: Evidence from the National Survey of Drug Use and Health. Addictive Behaviors, 69, 65-77.

Anderson, M. D., Hansen, B., \& Rees, D. I. (2013). Medical marijuana laws, traffic fatalities, and alcohol consumption. Journal of Law and Economics, 56, 333-369.

Andrews, C., Abraham, A., Grogan, C. M., Pollack, H. A., Bersamira, C., Humphreys, K., \& Friedmann, P. (2015). Despite resources from the ACA, most states do little to help addiction treatment programs implement health care reform. Health Affairs, 34, 828-835.

Angrist, J. D., \& Pischke, J. (2009). Mostly Harmless Econometrics: An Empiricist's Companion. Princeton, NJ: Princeton University Press.

Antwi, Y. A., Moriya, A. S., \& Simon, K. (2013). Effects of federal policy to insure young adults: evidence from the 2010 Affordable Care Act's dependent-coverage mandate. American Economic Journal: Economic Policy, 5, 1-28.

Autor, D. H. (2003). Outsourcing at will: The contribution of unjust dismissal doctrine to the growth of employment outsourcing. Journal of Labor Economics, 21, 1-42.

Azzone, V., Frank, R. G., Normand, S.-L. T., \& Burnam, M. A. (2011). Effect of insurance parity on substance abuse treatment. Psychiatric Services, 62, 129-134.

Bailey, J. (2014). The effect of health insurance benefit mandates on premiums. Eastern Economic Journal, 40, 119-127.

Bailey, J., \& Blascak, N. (2016). The effect of state health insurance benefit mandates on premiums and employee contributions. Applied Economics Letters, 23, 1042-1046.

Barry, C. L., \& Sindelar, J. L. (2007). Equity in private insurance coverage for substance abuse: a perspective on parity. Health Affairs, 26, w706-w716.

Bertrand, M., Duflo, E., \& Mullainathan, S. (2004). How much should we trust differences-indifferences estimates? The Quarterly Journal of Economics, 119, 249-275.

Besley, T., \& Case, A. (2000). Unnatural experiments? Estimating the incidence of endogenous policies. The Economic Journal, 110, 672-694.

Bondurant, S. R., Lindo, J. M., \& Swensen, I. D. (2016). Substance Abuse Treatment Centers and Local Crime. National Bureau of Economic Research Working Paper Series. 22610. National Bureau of Economic Research. Cambridge, MA. Retrieved from www. January 10, 2017.

Bound, J., Brown, C., \& Mathiowetz, N. (2001). Measurement error in survey data. Handbook of econometrics, 5, 3705-3843.

Buck, J. A. (2011). The Looming Expansion And Transformation Of Public Substance Abuse Treatment Under The Affordable Care Act. Health Affairs, 30, 1402-1410.

Busch, S. H., Epstein, A. J., Harhay, M. O., Fiellin, D. A., Un, H., Leader Jr, D., \& Barry, C. L. (2014). The effects of federal parity on substance use disorder treatment. The American Journal of Managed Care, 20, 76.

Cameron, A. C., \& Miller, D. L. (2015). A practitioner’s guide to cluster-robust inference. Journal of Human Resources, 50, 317-372. 
Cameron, A. C., \& Trivedi, P. K. (2005). Microeconometrics: methods and applications: Cambridge University Press.

Cawley, J., \& Ruhm, C. J. (2012). The economics of risky health behaviors. In M. V. Pauly, T. G. McGuire, \& P. P. Barros (Eds.), Handbook of Health Economics. Vol. 2 (pp. 95-199). New York: Elsevier.

Center for Behavioral Health Statistics and Quality. (2016). Key substance use and mental health indicators in the United States: Results from the 2015 National Survey on Drug Use and Health. (HHS Publication No. SMA 16-4984, NSDUH Series H-51). Retrieved from http://www.samhsa.gov/data/.

Centers for Disease Control and Prevention. (2015a). 10 Leading Causes of Injury Deaths by Age Group Highlighting Unintentional Injury Deaths, United States - 2015. Retrieved from https://www.cdc.gov/injury/images/lccharts/leading_causes_of_injury_deaths_unintentional_injury_2015_1050w760h.gif

Centers for Disease Control and Prevention. (2015b). http://www.cdc.gov/vitalsigns/drinkinganddriving/.

Dave, D., \& Mukerjee, S. (2011). Mental health parity legislation, cost-sharing and substanceabuse treatment admissions. Health Economics, 20, 161-183.

Dee, T. S., \& Evans, W. N. (2001). Behavioral policies and teen traffic safety. The American Economic Review, 91, 91-96.

Eisenberg, D. (2003). Evaluating the effectiveness of policies related to drunk driving. Journal of Policy Analysis and Management, 22, 249-274.

Eoh, H. J., Chung, M. K., \& Kim, S.-H. (2005). Electroencephalographic study of drowsiness in simulated driving with sleep deprivation. International Journal of Industrial Ergonomics, 35, 307-320.

Ettner, S. L., Harwood, J. M., Thalmayer, A., Ong, M. K., Xu, H., Bresolin, M. J., . . Azocar, F. (2016). The Mental Health Parity and Addiction Equity Act evaluation study: Impact on specialty behavioral health utilization and expenditures among “carve-out” enrollees. Journal of Health Economics, 50, 131-143.

Flood, S., King, M., Ruggles, S., \& Warren, J. R. (2015). Integrated public use microdata series, Current Population Survey: Version 4.0.[Machine-readable database]. Minneapolis: University of Minnesota.

Freeborn, B. A., \& McManus, B. (2010). Substance abuse treatment and motor vehicle fatalities. Southern Economic Journal, 76, 1032-1048.

French, M. T., \& Gumus, G. (2014). Macroeconomic fluctuations and motorcycle fatalities in the US. Social Science \& Medicine, 104, 187-193.

French, M. T., \& Gumus, G. (2015). Fast times during spring breaks: Are traffic fatalities another consequence? Economic Inquiry, 53, 745-757.

Golberstein, E., Busch, S. H., Zaha, R., Greenfield, S. F., Beardslee, W. R., \& Meara, E. (2015). Effect of the Affordable Care Act's young adult insurance expansions on hospital-based mental health care. American Journal of Psychiatry, 172, 182-189.

Goldman, H. H., Frank, R. G., Burnam, M. A., Huskamp, H. A., Ridgely, M. S., Normand, S.-L. T., .. . Busch, A. B. (2006). Behavioral health insurance parity for federal employees. New England Journal of Medicine, 354, 1378-1386.

Grossman, M. (1972). On the concept of health capital and the demand for health. Journal of Political Economy, 80, 223-255. 
Hack, M. A., Choi, S. J., Vijayapalan, P., Davies, R. J. O., \& Stradling, J. R. (2001). Comparison of the effects of sleep deprivation, alcohol and obstructive sleep apnoea (OSA) on simulated steering performance. Respiratory Medicine, 95, 594-601.

Houston, D. J., \& Richardson, L. E. (2008). Motorcyclist fatality rates and mandatory helmet-use laws. Accident Analysis and Prevention, 40, 200-208.

Jensen, G. A., \& Morrisey, M. A. (1999). Employer-sponsored health insurance and mandated benefit laws. Milbank Quarterly, 77, 425-459.

Klick, J., \& Stratmann, T. (2006). Subsidizing addiction: Do state health insurance mandates increase alcohol consumption? The Journal of Legal Studies, 35, 175-198.

Kline, P. (2011). The impact of juvenile curfew laws on arrests of youth and adults. American Law and Economics Review, 14, 44-67.

Koehler, S. A., \& Brown, P. A. (2009). Forensic epidemiology: CRC Press.

Kruskal, W. H., \& Wallis, W. A. (1952). Use of ranks in one-criterion variance analysis. Journal of the American Statistical Association, 47, 583-621.

Kunz, F. M., French, M. T., \& Bazargan-Hejazi, S. (2004). Cost-effectiveness analysis of a brief intervention delivered to problem drinkers presenting at an inner-city hospital emergency department. Journal of Studies on Alcohol, 65, 363-370.

Lo Sasso, A. T., \& Lyons, J. S. (2004). The sensitivity of substance abuse treatment intensity to co-payment levels. The Journal of Behavioral Health Services \& Research, 31, 50-65.

Lovenheim, M. F. (2009). The effect of teachers' unions on education production: Evidence from union election certifications in three midwestern states. Journal of Labor Economics, 27, 525-587.

Lu, M., \& McGuire, T. G. (2002). The productivity of outpatient treatment for substance abuse. Journal of Human Resources, 37, 309-335.

Maclean, J. C., Oney, M., Marti, J., \& Sindelar, J. L. (2018). What factors predict the passage of state-level e-cigarette regulations? Health Economics.

Maclean, J. C., Popovici, I., \& Stern, E. (2017). Health insurance expansions and provider behavior: Evidence from substance use disorder providers. National Bureau of Economic Research Working Paper Series. 23094. National Bureau of Economic Research. Cambridge, MA.

Maclean, J. C., \& Saloner, B. (2017). Substance use treatment provider behavior and healthcare reform: Evidence from Massachusetts. Health Economics.

Markowitz, S., \& Cuellar, A. (2007). Antidepressants and youth: Healing or harmful? Social Science \& Medicine, 64, 2138-2151.

McConnell, K. J., Ridgely, M. S., \& McCarty, D. (2012). What Oregon's parity law can tell us about the federal Mental Health Parity and Addiction Equity Act and spending on substance abuse treatment services. Drug and Alcohol Dependence, 124, 340-346.

McGinty, E. E., Busch, S. H., Stuart, E. A., Huskamp, H. A., Gibson, T. B., Goldman, H. H., \& Barry, C. L. (2015). Federal parity law associated with increased probability of using outof-network substance use disorder treatment services. Health Affairs, 34, 1331-1339.

McLellan, A. T., Lewis, D. C., O'brien, C. P., \& Kleber, H. D. (2000). Drug dependence, a chronic medical illness: implications for treatment, insurance, and outcomes evaluation. JAMA, 284, 1689-1695.

Meara, E., Golberstein, E., Zaha, R., Greenfield, S. F., Beardslee, W. R., \& Busch, S. H. (2014). Use of hospital-based services among young adults with behavioral health diagnoses before and after health insurance expansions. JAMA Psychiatry, 71, 404-411. 
National Center for Statistics and Analysis. (2016). State alcohol-impaired-driving estimates: 2014 data. (Traffic Safety Facts. Report No. DOT HS 812 264). Washington, DC.

National Highway Traffic Safety Administration. (2010). Drug involvement of fatally injured drivers. National Highway Traffic Safety Administration.

National Institute on Drug Abuse. (2012). Principles of drug addiction treatment: A researchbased guide. 3rd Edition. Retrieved from https://d14rmgtrwzf5a.cloudfront.net/sites/default/files/podat_1.pdf

Oberlander, J. (2010). Long time coming: why health reform finally passed. Health Affairs, 29, 1112-1116.

Popovici, I., \& French, M. T. (2013a). Binge drinking and sleep problems among young adults. Drug and Alcohol Dependence, 132, 207-215.

Popovici, I., \& French, M. T. (2013b). Economic evaluation of substance abuse interventions: Overview of recent research findings and policy implications. In B. S. McCrady \& E. E. Epstein (Eds.), Addictions: A comprehensive guidebook: Oxford University Press.

Popovici, I., French, M. T., \& McKay, J. R. (2008). Economic evaluation of continuing care interventions in the treatment of substance abuse: recommendations for future research. Evaluation Review, 32, 547-568.

Popovici, I., Maclean, J. C., Hijazi, B., \& Radakrishnan, S. (2017). The effect of state laws designed to prevent nonmedical prescription opioid use on overdose deaths and treatment. Health Economics. doi:10.1002/hec.3548

Rajkumar, A. S., \& French, M. T. (1997). Drug abuse, crime costs, and the economic benefits of treatment. Journal of Quantitative Criminology, 13, 291-323.

Reuter, P., \& Pollack, H. (2006). How much can treatment reduce national drug problems? Addiction, 101, 341-347.

Robinson, G. K., Connolly, J. B., Whitter, M., \& Magana, C. A. (2006). State Mandates for Treatment for Mental Illness and Substance Abuse Disorders. Retrieved from https://store.samhsa.gov/shin/content/SMA07-4228/SMA07-4228-A.pdf

Sabia, J. J., \& Nguyen, T. T. (2016). The Effect of Medical Marijuana Laws on Labor Market Outcomes. Discussion Paper No. 9831 IZA. Bonn, Germany.

Saloner, B., Antwi, Y. A., Maclean, J. C., \& Cook, B. (2017). Access to health insurance and utilization of substance use disorder treatment: Evidence from the Affordable Care Act dependent coverage provision. Health Economics. doi:10.1002/hec.3482

Saloner, B., \& Cook, B. (2014). An ACA provision increased treatment for young adults with possible mental illnesses relative to comparison group. Health Affairs, 33, 1425-1434.

Silva, J. S., \& Tenreyro, S. (2006). The log of gravity. The Review of Economics and Statistics, 88, 641-658.

Sommers, B. D., Arntson, E., Kenney, G. M., \& Epstein, A. M. (2013). Lessons from early Medicaid expansions under health reform: interviews with Medicaid officials. Medicare Medicaid Research Review, 3. doi:10.5600/mmrr.003.04.a02

Starr, S. B. (2002). Simple fairness: ending discrimination in health insurance coverage of addiction treatment. The Yale Law Journal, 111, 2321-2365.

Stewart, D., Gossop, M., \& Marsden, J. (2002). Reductions in non-fatal overdose after drug misuse treatment: results from the National Treatment Outcome Research Study (NTORS). Journal of Substance Abuse Treatment, 22, 1-9. 
Subramanian, R. (2002). Transitioning to multiple imputation-A new method to estimate missing blood alcohol concentration (BAC) values in FARS. (HS-809 403). Retrieved from https://crashstats.nhtsa.dot.gov/Api/Public/ViewPublication/809403

Substance Abuse and Mental Health Services Administration. (2011). Results from the 2010 National Survey on Drug Use and Health: Summary of National Findings. Retrieved from Rockville, MD: https://www.samhsa.gov/data/sites/default/files/NSDUHNationalFindingsResults2010web/2k10ResultsRev/NSDUHresultsRev2010.pdf December 15, 2017.

Substance Abuse and Mental Health Services Administration. (2016). Receipt of Services for Substance Use and Mental Health Issues among Adults: Results from the 2015 National Survey on Drug Use and Health. Retrieved from http://www.samhsa.gov/data/.

Swensen, I. D. (2015). Substance-abuse treatment and mortality. Journal of Public Economics, 122, 13-30. doi:http://dx.doi.org/10.1016/j.jpubeco.2014.12.008

Terán-Santos, J., Jimenez-Gomez, A., Cordero-Guevara, J., \& the Cooperative Group BurgosSantander. (1999). The association between sleep apnea and the risk of traffic accidents. New England Journal of Medicine, 340, 847-851.

The Beer Institute. (2012). The Brewer's Almanac 2012.

Wen, H., Cummings, J. R., Hockenberry, J. M., Gaydos, L. M., \& Druss, B. G. (2013). State parity laws and access to treatment for substance use disorder in the United States: implications for federal parity legislation. JAMA Psychiatry, 70, 1355-1362.

Wen, H., Hockenberry, J. M., Borders, T. F., \& Druss, B. G. (2017). Impact of Medicaid expansion on Medicaid-covered utilization of buprenorphine for opioid use disorder treatment. Medical Care, 55, 336-341.

Wen, H., Hockenberry, J. M., \& Cummings, J. R. (2017). The effect of Medicaid expansion on crime reduction: Evidence from HIFA-waiver expansions. Journal of Public Economics, 154, 67-94.

Wolfers, J. (2006). Did unilateral divorce laws raise divorce rates? A reconciliation and new results. The American Economic Review, 96, 1802-1820.

Zaloshnja, E., Miller, T. R., \& Blincoe, L. J. (2013). Costs of alcohol-involved crashes, United States, 2010. Annals of Advances in Automotive Medicine, 57, 3-12. 